\title{
A Market with Frictions in the Matching Process: An Experimental Study*
}

\author{
Timothy Cason and Charles Noussair
}

January 12,2004

\begin{abstract}
We construct a laboratory market with the structure of the theoretical model of Burdett, Shi, and Wright (2001). The model is a simple and natural way to represent a market in which there is a friction in the matching process between buyers and sellers. Sellers first simultaneously post prices at which they are willing to sell their single unit of a good. Buyers then simultaneously choose a seller from whom to attempt to purchase a unit. If more than one buyer chooses the same seller, the good is randomly sold to one of the buyers. If a seller is not chosen by any buyer, his unit is not sold. Our experimental results show a broad consistency with the model of Burdett et al. and less support for an alternative model, which is analogous to the model of Montgomery (1991), and which has different assumptions on the strategic interaction between sellers. The main departure that we observe from the Burdett et al. model is that prices exceed the equilibrium level when there are only two sellers.
\end{abstract}

\section{Introduction}

The classical model of perfect competition in microeconomics is frictionless in the sense that it contains an implicit assumption that buyers and sellers can coordinate so that no buyer who is willing to pay more than the market price and no seller with a marginal cost lower than the market price fails to make a trade. This coordination requires that the matching process not involve too many or too few buyers trying to purchase from an individual seller. If the matching process involves frictions and possible coordination failure, units must be rationed and

\footnotetext{
* Cason: Department of Economics, Krannert School of Management, Purdue University, 403 West State Street, West Lafayette, IN 47907-2056, USA. E-mail: cason@mgmt.purdue.edu. Noussair: Department of Economics, Emory University, Atlanta, GA 30322-2240. E-mail: cnoussa@emory.edu. We thank conference and seminar participants at the Economic Science Association conference, the International Industrial Organization Conference, Indiana University and Purdue University for helpful comments, Jeff Bayer and Emmanuel Dechenaux for research assistance, and the University Faculty Scholar program at Purdue University for financial support.
} 
inefficiency can result. Indeed, this type of friction characterizes typical markets where it is costly to travel from one seller to another and a buyer cannot observe the number of buyers approaching a seller he intends to visit. ${ }^{1}$

Burdett, Shi and Wright (2001), hereafter BSW, model a market with this type of friction in an elegant and general manner. Here, we focus on a special case of their model with the following structure. Sellers, who each have one unit of a good for sale, simultaneously post prices. Buyers observe prices and then have an opportunity to choose a seller from whom to attempt to purchase a unit. If more than one buyer attempts to purchase from the same seller, only one of the potential buyers, chosen at random, is able to make the purchase. The other buyer receives a payoff of zero. If no buyers visit a seller, the seller is unable to make a sale and also receives a payoff of zero. Thus the principal friction is that buyers must commit themselves to the seller from whom they will attempt to purchase before knowing the choices of other buyers. Rationing occurs if a seller faces excess demand. Units of sellers whom no buyers choose remain unsold.

In contrast to a frictionless setting in which buyers can always purchase from the lowpriced sellers, the sellers charging the lowest prices are not necessarily those who make the sales, since buyers may not all attempt to purchase from the lowest-priced sellers. For buyers there is a tradeoff: they can visit a lower-priced seller and receive a larger profit in the event they are able to purchase, or they can visit a higher-priced seller where there may be a higher probability of being able to make a purchase. For sellers, a tradeoff exists between charging a higher price and receiving a larger profit in the event of a sale and charging a lower price to increase the probability of making a sale. As in the Cournot model, sellers face a payoff function that is continuous in their strategy, which is their posted price, rather than the discontinuous payoff function that would exist in a pricing game with no frictions. There is generically a unique

\footnotetext{
${ }^{1}$ This situation can occur if sellers are in different locations and it takes time to travel between them. As Burdett et al. (2001) note, their model can also represent a market where a higher price is charged for a higher probability of service. The model is also applicable to a situation where individuals must choose a queue or a transportation route without knowing the choices of others, and where congestion reduces payoffs. Frictions and mismatches between quantities supplied and demanded are common in capacity-constrained markets, such as for real estate. An analogous friction to the Burdett et al. model occurs when prospective sellers must commit to a choice of buyer before observing other sellers' choices, as for example when a job-seeker responds to an employment advertisement that includes the wages offered.
} 
equilibrium to the game, aside from those that require implausible coordination. ${ }^{2}$ The equilibrium has the symmetry properties that all sellers charge the same price and each buyer visits each seller with equal probability.

In the BSW model all agents are strategic actors. Both sides make their decisions to maximize profit and there are no restrictions on the division of rents between the two sides of the market. An alternative set of assumptions underlies the model of Montgomery (1991), originally proposed to describe frictions in the labor market, in which the buyers (employers) post the prices (wages). In the analog to his model in which sellers post prices, sellers do not interact strategically, but instead behave as price takers who are constrained to ensure that buyers gain a minimum reservation level of surplus. Though these assumptions might be viewed as ad hoc, they are not unreasonable to those who study experimental markets. Competitive behavior on the part of sellers in a market is observed under many of the institutions of exchange that have been studied even when there are only a small number of sellers (Smith, 1982). Substantial evidence also indicates that people are reluctant to accept highly unfavorable divisions of surplus (e.g. Güth et al., 1982; Fehr and Schmidt, 1999).

In this paper we report an experiment that investigates the behavior of a market with frictions of the type described above. The structure of the economy and the nature of the friction parallel the BSW model, but also allow the Montgomery model to be applied in a straightforward manner. There are two treatments in our experiment. In the first treatment, 2seller, there are two sellers and three buyers in each market, and in the second treatment, 3seller, three sellers and two buyers comprise each market. We compare our data to the predictions of the BSW and the Montgomery models. Our choice to study a market with relatively few agents has some implications. It is the setting under which the two theoretical models make the most divergent predictions from each other, so it is optimal from the point of view of discriminating between theories. ${ }^{3}$ The existence of a small number of participants also potentially simplifies the calculation of optimal strategies, because sellers would have an easier time computing reaction functions for the strategies of a small number of competitors. Furthermore, buyers might find it

\footnotetext{
${ }^{2}$ Such coordination would require the buyers, who move simultaneously, to coordinate on specific sellers. In a oneshot game or under the random matching rule employed in our experiment it would seem implausible for this to occur. The unequal number of buyers and sellers would render coordination even more difficult.

${ }^{3}$ The two models' price predictions differ by 25-30 percent in the five-trader markets of our experiment. Increasing the market to include 25 traders with similar ratios of buyers and sellers, for example, leads to price predictions that differ by less than five percent.
} 
less demanding cognitively to randomize their choice of seller among fewer alternatives. On the other hand, a small market is the setting under which the assumption of non-cooperative behavior in the BSW model or of competitive behavior in the Montgomery model can most plausibly be called into question. Although there is more potential for collusive behavior when a small number of agents are on one side of the market, the experiment limits the potential for collusion by randomly re-grouping subjects each period in a "strangers" design.

The results of the experiment show that within individual sessions, prices converge towards a common price, as predicted by both models. The prices reflect the market pressures that underpin both models, but they are generally closer to the predictions of the BSW than the Montgomery model. The principal departures from the BSW model are that in the 2seller treatment, prices are higher, observed buyer demand is less elastic, and quantity exchanged is lower, than predicted. Our results are described in section four, after a brief review of the models and previous experiments in section two, and a summary of the experimental design in section three. Our conclusions are summarized in section five.

\section{The Models and Predictions}

\section{2a. The BSW model}

In the model of BSW there are $n$ buyers and $m$ sellers. Each buyer $i$ has a valuation $v_{i}=1$ for purchasing a unit of the good. Each seller can sell up to one unit and incurs no cost to do so. The game consists of two stages. In the first stage sellers simultaneously choose prices; $p_{j}$ denotes the price seller $j$ posts. In the second stage, buyers, after having observed the prices all sellers charge, choose a seller from whom to attempt to purchase. If no buyers choose a particular seller, that seller's profit is zero. If exactly one buyer chooses seller $j$, seller $j$ receives a profit of $p_{j}$ and the buyer receives profit $1-p_{j}$. If $k>1$ buyers choose seller $j$, the seller makes a profit of $p_{j}$, and one of the $k$ buyers is randomly chosen to purchase the unit. The buyer chosen receives a payoff of $1-p_{j}$, and the other $k-1$ buyers receive zero.

BSW solve for the generically unique subgame perfect equilibrium of the game that does not require coordination, for arbitrary $n$ and $m$. The equilibrium has the property that all sellers charge the same price and buyers visit each seller with equal probability. ${ }^{4}$ This is the most

\footnotetext{
${ }^{4}$ They also characterize equilibria for the $n=m=2$ case that involve coordination, in which sellers choose unequal prices and buyers approach certain sellers with probability one. These coordinated equilibria may be plausible for
} 
plausible equilibrium that might emerge in our experiment, because all sellers as well as all buyers are identical in terms of position in the game and objective function. Furthermore, the random re-matching in our experiment makes coordination on an asymmetric equilibrium highly improbable. In the equilibrium each seller charges a price equal to:

$$
P_{B}(m, n)=\frac{m-m\{1+[n /(m-1)]\}[1-(1 / m)]^{n}}{m-\{m+[n /(m-1)]\}[1-(1 / m)]^{n}}
$$

and each buyer attempts to purchase from each seller with probability $1 / m$. The expected number of sales due to successful buyer-seller matches, which BSW call the equilibrium matching function, is

$$
M(m, n)=m\left[1-(1-1 / m)^{n}\right]
$$

\section{2b. The Montgomery model}

Montgomery's (1991) model of the labor market considers a situation where prospective employers post wages simultaneously. This is followed by the choice of employer on the part of workers. A version of the model in which the sellers post prices and buyers choose a seller from whom to attempt to purchase yields alternative predictions to BSW for the outcomes of the game they model. The difference between the two models is that Montgomery assumes a different individual rationality constraint than BSW. In BSW's model, a buyer's individual rationality constraint is that his surplus must be non-negative, that is, $U \geq 0$, and is not binding in equilibrium. In contrast, in Montgomery's model, the seller is required to give the buyer a "market" level of surplus. This surplus is equal to the payoff a buyer could receive from going to another seller. The individual rationality constraint for buyers is binding in equilibrium. Each seller is also acting as a price taker in Montgomery's model, taking a market price as given, and

environments with non-market communication or repeated interaction between the same traders, but not in our environment with no non-market communication and randomly rematched subjects. 
thus is not involved in a strategic interaction with the other sellers. The equilibrium price in the Montgomery model is equal to: ${ }^{5}$

$$
P_{M}(m, n)=1-\frac{n[1-(1 / m)]^{n-1}}{m\left\{1-[1-(1 / m)]^{n}\right\}} .
$$

Although the equilibrium prices differ between the BSW and the Montgomery models, the probability of matching is the same since sellers charge the same price and buyers visit each seller with equal probability. Therefore, equation (2) also specifies the expected number of sales in the Montgomery model. Because of the lower transaction prices in the Montgomery model, sellers' expected profits are lower and buyers' expected payoffs are higher than in the BSW model.

\section{2c. Previous experimental research}

Previous laboratory studies of posted offer markets in frictionless environments have documented some clear empirical patterns (see chapter 4 of Davis and Holt (1993) for a survey). A main finding from previous research is that prices and quantities traded converge to the competitive equilibrium when sellers do not have market power. Convergence toward the competitive price usually occurs from above; that is, initial prices in experimental sessions tend to be higher than predicted (Plott and Smith, 1978; Ketcham et al., 1984). The direction of convergence is independent of the equilibrium surplus division between buyers and sellers (Davis and Williams, 1986). If there exist Nash equilibria with supercompetitive prices, there is a tendency for prices to converge to levels that exceed the competitive equilibrium. Supercompetitive pricing is also more likely with a relatively small number of sellers (e.g., Fouraker and Siegel, 1963). Alger (1987) finds that collusive outcomes are often attained in experiments with 150 periods, an unusually long time horizon for economic experiments when there are two sellers interacting repeatedly, while such outcomes occur only about one-third of the time with three sellers. Dufwenberg and Gneezy (2000) observe supercompetitive pricing with two sellers (but not with three or four sellers), even when sellers are randomly re-grouped

\footnotetext{
${ }^{5}$ The equilibrium prices in equations (1) and (3) are different for all finite $m$ and $n$, but BSW show that they are arbitrarily close together in large markets. In particular, if $b=n / m$ is fixed, then as $m, n \rightarrow \infty, P_{B}, P_{M} \rightarrow 1-\left(b / \mathrm{e}^{b}-\right.$ 1). The two models differ in that the BSW model, in contrast to the Montgomery model, allows individual sellers to exploit their market power in choosing prices. However, this ability disappears as the market becomes large.
} 
each round. Cason and Williams (1990) study a frictionless environment that is similar to the current study in that all sellers have constant and equal marginal costs and all buyers have constant and equal unit valuations, but with four buyers and four sellers. They observe prices that correspond to the competitive level, even though nearly all of the surplus accrues to one side of the market in equilibrium. Since our setting is very different from the frictionless environment in previous studies it is not clear whether any of these patterns would carry over to our experiment.

Researchers have introduced frictions in laboratory posted offer markets through buyer search costs. Abrams et al. (2000) study a posted offer market with search, and include a treatment in which equilibrium prices correspond to the monopoly level because buyers obtain only one price quote per search (Diamond, 1971). They find that most prices are closer to the price range midpoint that splits the exchange surplus than to the predicted level. Davis and Holt (1996) obtain similar results. On the other hand, in three of four relevant trial sequences, Grether, Schwartz and Wilde (1988) observe results closer to the Diamond (1971) extreme in an experiment that featured anonymous sellers and public information on the previous period's price distribution. Cason and Friedman (2003) study an environment in which buyer search costs lead to equilibrium price dispersion, and observe prices that correspond to the equilibrium price range. However, they clearly reject the mixed strategy equilibrium because sellers' posted prices have significant positive autocorrelation and cross sectional correlation. In contrast to this previous research on posted offer markets with frictions, the present experiment introduces frictions through mismatching and rationing. Buyer search costs play no role.

\section{The Experiment}

The four sessions reported in this study were conducted at the Vernon Smith Experimental Economics Laboratory at Purdue University in the spring of 2002. All 95 subjects were undergraduate students at Purdue University recruited from introductory economics courses. No subject participated in more than one session of the study. Some subjects had participated in earlier economics experiments, but all were inexperienced in the sense that they had never taken part in an earlier session of this type. Table 1 outlines the name and date of each session, the number of participants, the number of buyers and sellers in each group, and the price predictions of the BSW and the Montgomery models. In the 2seller treatment each group consisted of two sellers and three buyers, while in the 3 seller treatment each group had three sellers and two 
buyers. In both treatments the groups were of size five and there were a minimum of 20 subjects in each session.

\section{[Table 1: About Here]}

Appendix A contains the instructions given to subjects in the 2seller treatment. The instructions for the 3-seller treatment are identical except for the references to the number of buyers and sellers. The experiment was completely computerized other than the experimenter reading aloud the instructions after they were handed out to participants. The computer program used the z-Tree toolbox developed at the University of Zurich (Fischbacher, 1999). In each session there were fifty periods and a random matching rule was in effect. That is, each player was randomly regrouped with other buyers and sellers in each period so that he had an equal probability of being grouped with each seller and each buyer in the session. Subject roles were fixed, however, so that once randomly assigned to a buyer or seller role in period 1, a subject always remained in this role.

As noted in the introduction, we chose to randomly regroup subjects each period in order to minimize the potential for collusion, since the theory the experiment tests is based on a static, one-shot game. Approximating a one-shot game also requires that a relatively large (by the standards of economic experiments) number of subjects be present at each session to lower the probability of repeated matching with the same group members. The cost of these design decisions is that it limits the number of statistically independent observations generated. Consequently, it is inappropriate to use simple statistical tests (e.g., $t$-tests or nonparametric tests) that require a large number of independent observations. Generating many independent observations for a market like this is not feasible for reasonable experimental research budgets. Fortunately, we can nevertheless make correct statistical inferences by using panel data econometric methods that correctly model the dependence of observations and errors arising from repeated measures drawn on the same set of subjects. These include random effects models for the error term for subject-level analyses of price choices and buyer purchase decisions, and fixed effect models for session-level analyses of price variance or matching efficiency.

In each period the sequence of events was as follows. Sellers each chose a price between 0 and 1000 francs by typing in a number on a field on their computer screen. After all sellers had 
chosen their prices, buyers' computer screens displayed all of the prices submitted by the two or three sellers in their own group. Seller identities were never revealed. Buyers could then select any one of the sellers from whom to attempt to purchase or could elect not to make a purchase. They did not observe the choices of any other buyers at the time they made this decision. After all buyers made their choices, the screen of each subject in the group displayed the prices posted by each seller in their group, the number of buyers who chose each seller, the subject's own earnings for the period, and the subject's own accumulated earnings until the current point in the session. Subjects never observed buyer and seller identities, and subjects were randomly regrouped into new markets before the start of each new period.

The values of parameters in the experiment were the following. In both treatments, $v_{i}=$ 1000 "francs", units of an experimental currency. The earnings for a seller were equal to the price he charged if he made a sale and zero if he did not make a sale. A buyer earned 1000 minus the price she paid if she purchased a unit and zero if she did not make a purchase. Francs were converted to US dollars in the calculation of subjects' final earnings at a rate of 500 francs to $\$ 1$ for buyers and 1500 to $\$ 1$ for sellers in the 2 seller treatment. They were exchanged at 1500 to $\$ 1$ for buyers and 500 to $\$ 1$ for sellers in the 3seller treatment. The differential conversion rates were private information and were selected due to the differences in equilibrium prices and surpluses in the two treatments. The sessions lasted about 75 minutes and subjects earned salient rewards of about $\$ 20$ each on average.

\section{Results}

\subsection{Market behavior}

Prices: Figure 1a displays the time series of average posted prices and their variances in the four sessions, each of which consisted of four to five simultaneous markets in operation for 50 periods. The variance calculation uses each individual seller's price offer during a period as an observation. Figure $1 \mathrm{~b}$ illustrates a similar time series for all transaction prices. The transaction prices are slightly lower than the posted prices because higher offers have a lower probability of resulting in a transaction, particularly in the 3 seller case. In the initial periods, prices are dispersed and often in the middle range of feasible prices (400-600 francs). These early prices tend to split the available exchange surplus more equally than the models predict. This may occur because fairness rather than strategic concerns dominate the early price choices, or because 
relatively equal surplus division is a behavioral property of the particular institution when it is first introduced to inexperienced subjects in our environment. These figures clearly illustrate the importance of providing market feedback, however, because within five to ten periods prices adjust upward in 2seller and downward in 3seller in the direction of the models' predictions. Other than perhaps in the final two periods where an endgame effect seems to occur, the variance of transaction prices generally declines over time. Thus, within each session, the prices are converging toward a common value. This is consistent with both the BSW and the Montgomery models, in which all trades occur at the same price in equilibrium.

The figure also indicates that prices in the 2seller treatment converge to a level higher than the prediction of either model, though the level is closer to the BSW prediction than the Montgomery prediction. In periods 39-48, the last ten periods before the endgame effect in periods 49-50 occurs, the average posted prices are 839 and 836 in these two sessions. In the 3 seller treatment, posted prices converge to a level closer to the Montgomery prediction of 200 in one session, with an average price of 220 in periods 39-48; and prices converge to a level closer to the BSW prediction of 273 in the other session, with an average price of 286 in periods 39-48. The time series of prices in the individual sessions of the 3 seller treatment reflect considerable persistence, as the session that begins with higher prices converges to a higher price.

[Figure 1: About Here]

To study the convergence process in more detail, we apply an extension of a statistical model, first used in Noussair et al. (1995), to the posted and transaction price data. The model summarizes the price patterns succinctly and projects the level towards which prices approach asymptotically:

$y_{i t}=\beta_{11} D_{1}(1 / t)+\beta_{12} D_{2}(1 / t)+\beta_{21} D_{1}((t-1) / t)+\beta_{22} D_{2}((t-1) / t)+u_{i t}$,

where $i$ indexes the session, the $D_{i}$ dummy variables take on a value of 1 for the indicated session within each treatment, and $t$ represents the market period. Notice that in the first period $(t=1)$ the $(t-1) / t$ terms are zero. Thus a $\beta_{1 i}$ coefficient provides an estimate of the value of the dependent 
variable at the beginning of session $i$. As $t \rightarrow \infty$, the $1 / t$ terms approach zero while the $(t-1) / t$ terms approach one so the $\beta_{2 i}$ coefficients indicate the asymptote of the dependent variable in session $i$. Table 2 reports versions with separate session asymptotes as well as the specification used by Noussair et al. (1995) that imposes a common asymptote $\beta_{21}=\beta_{22}=\beta_{2}$. The estimates all correct for first-order autocorrelation and model the panel nature of the dataset with subject-specific random effects. Periods 49 and 50 are not included due to the clear price divergence shown in Figure 1 for these late periods, rendering the specification inappropriate for those two periods.

The results shown in Table 2 provide statistical evidence consistent with the visual impression Figure 1 creates. The regressions have high statistical power since each individual seller's price in each period is an observation. Consequently, application of an F-test rejects the hypothesis of a common asymptote $\left(\beta_{21}=\beta_{22}\right)$ for both posted prices and transaction prices in both treatments at the $p<.01$ level. This is the case even in the 2seller treatment where the difference between sessions is relatively minor. ${ }^{6}$ Likewise, a comparison of the $\beta_{2 \mathrm{i}}$ terms with the predictions of the BSW and Montgomery models rejects the hypotheses that posted and transaction prices are converging to the predicted levels under either model at the $p<.01$ level, except for the posted prices in the 3seller treatment, which are not significantly different from the BSW model prediction. All of the $\beta_{2}$ terms are closer to the prediction of the BSW than the Montgomery model. Furthermore, six of eight $\beta_{2 \mathrm{i}}$ terms are closer to the BSW than the Montgomery prediction. To summarize:

[Table 2: About Here]

Result 1: The BSW model is a more accurate predictor of the prices to which the markets converge than the Montgomery model. Average prices converge to values closer to the BSW prediction than the Montgomery prediction, with the exception of one of the sessions in the 3seller treatment. There is considerable heterogeneity between sessions.

Price Dispersion: Both models predict common prices for all sellers, and therefore zero price dispersion. Figure 1 indicates that dispersion tends to decline over time until the final couple of

\footnotetext{
${ }^{6}$ Part of the reason that the estimated asymptotes differ is that the early-period prices are lower in session 2seller-2, and this draws down the estimated asymptote for this session in this simple but relatively inflexible specification.
} 
periods. The top half of Table 3 evaluates the hypothesis that price dispersion, defined as the variance of prices across all sellers in a session, approaches zero asymptotically using the same regression models as in Table 2 . In the estimation, the variance of posted prices is used as the dependent variable. The results are qualitatively similar when using alternative dispersion measures such as the standard deviation of prices or the range of prices (i.e., maximum minimum posted price). Because variance is nonnegative, we use a Tobit model in the price dispersion regressions reported in Table 3 . The fact that all of the $\beta_{2}$ and the $\beta_{2 \mathrm{i}}$ terms are closer to zero than the corresponding $\beta_{1 \mathrm{i}}$ terms indicates a clear decline in variance over time within sessions. However, for all but one of the two 2seller sessions, price dispersion remains significantly positive even asymptotically. Comparison of the $\beta_{2}$ and the $\beta_{2 \mathrm{i}}$ terms in the two different treatments indicates that price dispersion is greater in 3seller than 2seller in the later periods. An F-test of the restriction $\beta_{21}=\beta_{22}$ is significant for both treatments (although only marginally in 3 seller with $p=0.057$ ), indicating that price variance, though declining over time in all sessions, is heterogeneous between sessions of the same treatment. In summary:

[Table 3: About Here]

Result 2: Patterns of price dispersion are consistent with convergence to common prices within sessions. Price dispersion (a) declines over time in all sessions; (b) converges to zero in one of the four sessions; and (c) is greater in the 3seller treatment than in the 2seller treatment.

The Matching Rate: Both models predict the same equilibrium quantity of trade in each period because they both assume that each buyer visits each seller with equal probability. From equation (2), the expected number of sales in each 5-trader market is 1.67 in the 3 seller treatment and 1.75 in the 2 seller treatment. Figure 2 displays the mean number of matches for the four sessions, shown as 10-period moving averages because of the substantial variation across periods. In the two sessions of the 3 seller treatment, the average number of matches per fivemember group was 1.68 and 1.59. In the two sessions of the 2seller treatment, the average number of matches per group was 1.62 and 1.68. The actual number of trades was thus close though on average slightly less than the predicted number, indicating no successful coordination 
on the part of buyers onto particular sellers. (Recall that groups were randomly reassigned each period, which makes coordination very difficult.)

\section{[Figure 2: About Here]}

We can equivalently express the number of matches in terms of a "friction rate," defined as the probability of only one rather than two trades. Both models predict that two trades occur with probabilities of $2 / 3$ in the 3 seller treatment and $3 / 4$ in the 2 seller treatment, which implies equilibrium friction rates of $1 / 3$ in the 3 seller treatment and $1 / 4$ in the 2 seller treatment. ${ }^{7}$ The bottom half of Table 3 presents a set of probit models used to study the friction rates observed in the experiment. We test the hypotheses that $\beta_{2}$ equals 0.675 , which is equivalent to a probability of two matches occurring of $3 / 4$ for the 2 seller treatment, and that $\beta_{2}$ equals 0.43 for a predicted two-match rate of $2 / 3$ in 3 seller. These $\beta_{2}$ values are the levels of the standard normal CDF, used in the probit model, that correspond to these match rates. The data do not reject the predicted 3 seller match rate of $2 / 3$, but they strongly reject the predicted 2 seller match rate of $3 / 4$. Traders in the 2seller treatment experience more frictions than predicted by the models. Indeed, the match rate in both treatments is similar to the $2 / 3$ rate predicted for the 3 seller treatment. If all of the match rate data are pooled, we fail to reject the hypothesis that the match rate is equal in the two treatments at the 5 percent level $(p$-value $=0.937)$. Thus, while the data strongly support the comparative static predictions of the theoretical models with regard to prices, they are not consistent with the comparative static predictions for the friction rate.

Result 3: The friction rate is consistent with the predictions of both models in the 3seller treatment. However, traders experience more frictions than the models predict in the 2seller treatment.

Although our analysis of aggregate market behavior indicates that the BSW model is more consistent with our data than the Montgomery model, it identifies two major deviations

\footnotetext{
${ }^{7}$ These markets have at least one transaction unless all buyers in the same market simultaneously refuse to purchase in a particular period. In only a total of two instances out of the 2350 buyer purchase opportunities over the four sessions did a buyer choose not to attempt to purchase from any seller. Every single period had at least one transaction.
} 
from the BSW model's predictions: (1) prices that exceed the predictions of the models in the 2seller treatment; and (2) a friction rate that exceeds the model's predictions in the 2seller treatment. The next two subsections investigate buyer and seller behavior in the 2 seller treatment in greater detail to try to identify the source of these deviations. Our analysis is structured in relation to the BSW model since prices are more consistent with its predictions than with those of the Montgomery model.

\subsection{Buyer Behavior}

We argue below that in the 2 seller treatment, the average transaction prices in excess of the BSW prediction documented in the last subsection are accompanied by inelastic market demand. More specifically, demand is less elastic than predicted with respect to differences between the prices of the two sellers when seller price differences are large. Overall in the 2 seller treatment, the seller charging the lower price makes 57.6 percent of all sales and the seller charging the higher price makes 42.4 percent of all sales. Although offer prices are equal in equilibrium, the equilibrium outcome emerges from the use of an optimal purchase rule on the part of buyers, and optimal price setting behavior on the part of sellers. The deviations from equilibrium outcomes that we observe in our data may merely reflect suboptimal behavior on the part of the seller side of the market. Buyers' purchase behavior may still be optimal given the prices sellers have chosen, even though the prices differ from the model's predictions and result in subgames off of the equilibrium path being reached. This possibility is not unreasonable given the relative simplicity of the buyer's decision, which merely requires choosing between visiting seller A, visiting seller B, and not attempting a purchase. Furthermore, a buyer's decision takes place after prices are known. The seller's decision, in contrast, involves choosing from 1000 possible prices, and anticipating the prices of competing sellers and the purchase behavior of buyers.

Consider the problem facing one of the three buyers in this treatment. Following BSW and normalizing the buyer value to 1 , denote as $\theta$ the probability that the other two buyers attempt to purchase from seller A. The expected profit for this buyer when attempting to purchase at price $p_{A}$ from seller $\mathrm{A}$ is

$\mathrm{E} \pi_{\text {buyer }}($ seller $\mathrm{A})=\left(1-p_{A}\right)\left[\theta^{2} / 3+\theta(1-\theta)+(1-\theta)^{2}\right]$ 
and the expected profit when attempting to purchase at price $p_{B}$ from seller $\mathrm{B}$ is

$\mathrm{E} \pi_{\text {buyer }}($ seller $\mathrm{B})=\left(1-p_{B}\right)\left[\theta^{2}+\theta(1-\theta)+(1-\theta)^{2} / 3\right]$

For this buyer to adopt a mixed strategy of purchasing from a seller with a probability other than zero or one, the expected profits from visiting seller A and seller B must be equal. A little algebra reveals that the critical probability $\theta^{*}$ that makes this buyer indifferent between the two sellers is

$$
\theta^{*}=\frac{2-1.5 p_{A}-0.5 p_{B}-0.5 \sqrt{16-16\left(p_{A}+p_{B}\right)+22 p_{A} p_{B}-3\left(p_{A}^{2}+p_{B}^{2}\right)}}{p_{B}-p_{A}}, \text { for } p_{A} \neq p_{B}
$$

If the difference in prices is great enough, then buyers do not play a mixed strategy and all three go to the lower-priced seller with probability one. ${ }^{8}$ Of course, for $p_{A}=p_{B}$ the critical $\theta^{*}=0.5$.

Figure 3 illustrates how this critical probability $\theta^{*}$ varies for some different combinations of prices for the two sellers. These equilibrium "demand curves" for seller B are decreasing in B's price and shift up as seller A raises her price. Buyers in the 2seller treatment face equal prices in less than 9 percent of the periods, and in less than 3 percent of the periods the price difference is great enough that buyers would strictly prefer one seller and play the pure strategy of attempting to purchase from him with probability one. For the other 88 percent of the periods, equation (7) describes the rate that buyers approach the low priced seller in the Nash equilibrium of the subgames resulting from the prices the sellers have posted.

\section{[Figure 3: About Here]}

These equilibrium purchase probabilities for the subgames actually played by buyers in the two seller treatment are consistent with observed deviations from the model's equilibrium friction rate. The equilibrium friction rate of 0.25 in the 2 seller treatment assumes that the two sellers post equal prices. In this case the three buyers would go to the two sellers with equal

\footnotetext{
${ }^{8}$ This occurs, for example, when one seller posts a price of 0.4 and the other seller posts a price of 0.85 . In this case a one-third chance of buying at a price of 0.4 (with a buyer value of 1) gives an expected payoff of 0.2 , which exceeds the expected payoff of buying at 0.85 with certainty (which gives a payoff of 0.15 ).
} 
probability, so all three would approach the same seller (resulting in a friction) with probability $(1 / 2)^{3}+(1-1 / 2)^{3}=0.25$. But any price dispersion changes the equilibrium $\theta^{*}$ for that particular subgame and raises the friction probability above 0.25 . Calculation of the $\theta^{*}$ for every combination of prices buyers actually faced in the 2 seller treatment, results in a predicted friction rate of 0.36 . This is almost exactly equal to the 0.35 observed friction rate in the 2 seller treatment.

Although the overall friction rate is consistent with optimal behavior on the part of buyers given actual prices, it appears to be largely due to the averaging of behavior over a large number of decisions. At the level of the individual observation, there are inconsistencies between the rate at which buyers approach the low-price seller and the rate equation (7) implies. Figure 4 presents a comparison between the observed rate that buyers approach the low priced seller to the rate at which buyers would be indifferent between the sellers (based on equation (7)) using all periods of the 2 seller treatment. When seller prices are similar so that buyers exhibiting equilibrium behavior approach sellers with approximately equal probability (the lower left region of the figure), the data show that buyers tend to be overly responsive to price differences. For example, when equation (7) indicates that buyers approach the low-price seller with probability 0.55 , we observe buyers approaching the low-price seller 62 percent of the time. However, when price differences between sellers are relatively large and imply higher predicted rates of approaching the low-price seller, buyers tend to be underresponsive to price differences. For example, when equation (7) indicates that buyers approach the low-price seller with probability 0.86 , we observe buyers approaching the low-price seller only 69 percent of the time. ${ }^{9}$ Thus, a buyer's decision to attempt to purchase from the low-priced seller is less dependent on the magnitude of the price difference between the two sellers than in the BSW model.

\section{[Figure 4: About Here]}

Table 4 presents estimates of two behavioral models of the buyer decision regarding whether or not to approach the low-price seller in a particular period. The dependent variables in these probit models equal one when the individual buyer approaches the seller with the lowest price. The independent variables include the predicted probability under the BSW model, and a

\footnotetext{
${ }^{9}$ Over two-thirds (69\%) of the observed price differences imply probabilities of approaching the low-price seller of 0.66 or lower.
} 
dummy variable that equals one if the buyer approached the low-priced seller in the immediately preceding period. Other variables in the regression are whether or not the previous attempt to purchase from the low-priced seller was successful or not, the number of other buyers attempting to purchase from the low-priced seller in the preceding period, and the total number of periods in the session until the current point. We exclude the 9 percent of the periods in which buyers face equal prices. As with the seller results presented above, we estimate the model with a random subject effects error specification. This properly adjusts the variance estimates to account for the multiple observations on individual buyers.

The results in columns (1) and (2) for the 2seller treatment indicate that an increase in the model's equilibrium probability of approaching the low-price seller $(\theta)$ is strongly associated with a greater likelihood of actually approaching the low-price seller. But the estimates indicate that buyers are less responsive to the price differences according to the reaction function underlying the mixed strategy equilibrium of the BSW model. In particular, evaluated at the means of the explanatory variables, the marginal impact of an increase in $\theta$ is about 0.613 for both models shown in columns (1) and (2), which is significantly less than one, the predicted value. The other significant regressor in columns (1) and (2) is the number of other buyers who approached the low-price seller in the previous period. If more buyers approach the low-price seller, it raises the probability that a buyer would experience a friction when approaching the low-price seller. The negative coefficient estimate on this term suggests that buyers react toward the experience of observing a potential friction by reducing the rate that they also approach the low-price seller in the next period. Result 4 summarizes our findings on buyer behavior for the 2seller treatment:

[Table 4: About Here]

Result 4: In the 2seller treatment, the friction rate is consistent with the BSW model predictions of buyer behavior in the subgames reached after sellers post prices. The two main discrepancies between observed buyer behavior and model predictions are that (1) buyers are insufficiently sensitive to the differences between seller prices, exhibiting demand less elastic than predicted under the model, and (2) buyers respond to the activity in the preceding period when making a choice of seller. 
Columns (3) and (4) of Table 4 provide evidence, in contrast, that the buyers in the 3 seller treatment are appropriately sensitive to the price differences and approach the low-price seller at approximately the optimal rate. The equilibrium probability of approaching the lowprice seller $(\theta)$ strongly predicts the observed probability of approaching the low-price seller. More importantly, the estimates indicate that the mixed strategy equilibrium correctly predicts buyers' responsiveness to seller price differences. Evaluated at the means of the explanatory variables, the marginal impact of an increase in $\theta$ is about 1.17 for both models shown in columns (3) and (4), which is not significantly different from one. That is, a predicted increase in the probability of approaching the low-price seller is matched with a statistically similar increase in these models' estimated probability of approaching the low-price seller. The other significant explanatory variables in columns (3) and (4) indicate that the buyer's experience in the previous period is a source of deviations from the model's predictions at the individual level. In particular, a buyer tends to increase his probability of approaching the low-price seller if he succeeded in purchasing from the low-price seller in the previous period or if the other buyer in his market did not approach the low-price seller in the previous period.

Result 5: Buyers in the 3seller treatment respond to differences in seller prices in a manner consistent with the BSW model. The main exception is that there is some tendency to also respond to the outcomes experienced in the previous period.

\subsection{Seller Behavior}

A natural question to ask is whether the buyer deviations from the equilibrium purchase probabilities are sufficient to cause best-responding sellers to price above the BSW prediction in the 2 seller treatment. The direction of the deviations in sellers' posted prices from equilibrium appears intuitive, since inelastic demand in the 2seller treatment permits sellers to profitably raise prices above the equilibrium. But do the buyers deviate from an optimal purchase rule enough to make the observed price choices optimal for the sellers?

We conduct the following numerical calculations to address this question. We first summarize the buyer purchase decisions indicated on Figure 4 using a weighted linear OLS regression. Each observation is weighted by the number of price combinations that are consistent 
with the indicated probability. The predicted probabilities near $1 / m$ receive more weight in the regressions because there are more price combinations that lead to nearly equal probabilities. We then determine the sellers' best response to this (smoothed) observed buyer acceptance behavior, taking into account the sellers' strategic interaction.

The results suggest that this exercise yields at least a partial explanation of the price deviations from the BSW model. In the 2seller treatment, best response to the observed buyer behavior is to post a price of 791. As expected, this exceeds the BSW model prediction of 727 , and it is closer to the low 800s price range that sellers choose in the later periods of this treatment (Figure 1). Similar calculations for the 3seller treatment indicate that the sellers' best response is to post prices of 256. This is only slightly below the BSW model prediction of 273, and it is also within the observed 220-286 range for late period average prices in this treatment. ${ }^{10}$ This is summarized as Result 6.

Result 6: In the two-seller treatment, the above-equilibrium prices chosen by sellers are consistent with best response behavior to buyers' revealed demand curves.

The behavioral models in Table 4 estimated for buyers suggest some dynamics from period to period that might conceivably lead to deviations of prices from equilibrium. Table 4 indicates that buyers respond along the lines of simple reinforcement and belief learning rules to the level of risk of frictions in the previous period. In particular, some buyers apparently respond to the increased probability of a friction on the low-priced seller (i.e., more buyers approaching the low-price seller in the previous period) by going to a higher priced seller in the next period. We consider here whether changes in seller behavior also occur in response to previous market activity.

Table 5 reports the results of the estimation of a model of the sellers' decision to change prices. The independent variables are whether the seller sold a unit in the pervious period, the average of the competing sellers' prices over the previous five periods, and whether a friction occurred in the previous period. The dependent variable is the change in price between the preceding and the current period. The models are estimated separately for the 2 seller and 3 seller

\footnotetext{
${ }^{10}$ The sellers best responses of 791 and 256 in the 2 seller and 3seller treatments respectively are remarkably close to the estimated asymptotes of posted prices as $t \rightarrow \infty$ of 792 and 264 reported in Table 2. This suggests that with experience observing buyer behavior, sellers are making better decisions over time.
} 
treatments, and the estimates are corrected for the significant negative autocorrelation in the price changes. The error term is also specified with random subject effects. In both treatments, a seller charges a higher price if he sold a unit in the previous period than if he did not. When a seller has failed to make a sale, he adapts on average by charging a lower price in the next period than he would had he succeeded in making a sale. As in the case of buyer behavior, the results suggest an adaptive response to the outcomes of previous periods. While the coefficient on the friction indicator for the previous period is positive, as might be expected, it is neither statistically significant nor large in size. The estimates in the table also show that despite the fact that prices are strategic complements, the effect of the other sellers' price in the previous five periods is negative in the 2 seller treatment and insignificant in the 3 seller treatment. ${ }^{11}$ This means that in the 2seller treatment, if overall market prices are relatively low, an individual is more likely to raise his price in the next period. The inelasticity of demand with respect to the price differences between sellers in the 2seller treatment suggests that such price increases are likely to be profitable. In the 3seller treatment, no significant price change in response to others' prices was observed.

[Table 5: About Here]

\section{Conclusion}

In this paper we report an experiment that studies a basic type of market friction. If a buyer cannot observe which seller that other buyers intend to purchase from, a coordination failure can arise in which, even if all prices are at an equilibrium level, there may be excess demand at one seller's location and excess supply at another seller's location. This type of friction is elegantly modeled by BSW (2001) and Montgomery (1991), using alternative assumptions on the nature of competition. Our experimental design allowed us to evaluate some of the predictions of each model.

We find that the BSW model characterizes the data more accurately than the Montgomery model. Behavior in the 3 seller treatment is quite consistent with the BSW model.

\footnotetext{
${ }^{11}$ We obtain similar results using the other sellers' prices in the most recent previous period instead of the average over the previous five periods. Table 5 reports estimates based on the longer time frame of five periods because groups are randomly re-matched each period., Only looking back at one period might not provide the seller with a very accurate estimate of other sellers' previous prices, and it would seem that the typical seller would use a longer horizon to determine his pricing decision.
} 
However, in the 2seller treatment, substituting subject behavior for model assumptions leads to two principal departures from the BSW model's predictions. The first is that average prices exceed the predictions of the BSW model, and the second is that market frictions are more frequent than predicted when there are two sellers. These effects are not observed in the 3seller treatment, for which the BSW model predicts average prices and trading patterns very well.

Also, and perhaps not surprisingly, convergence to a common price for all sellers is not complete. We show that this small heterogeneity in prices can provide an explanation for the higher friction rate relative to the equilibrium rate in the 2seller treatment. Buyers' are also less sensitive to price differences in this treatment than the model's prediction and do not approach the low-price seller with sufficient frequency. Consequently, buyer "demand" (in terms of the revealed willingness to pay rather than in terms of the underlying incentive structure) in the 2seller treatment is less elastic in the price differences between sellers than in equilibrium. In perhaps serendipitous recognition of this phenomenon, the sellers in the 2seller treatment behave as if they are aware of the inelasticity of demand and post prices above equilibrium levels. Future research could verify this interpretation by using robot buyers employing arbitrary demand behavior and considering whether sellers' posted prices converge to the optimum conditional on buyers' decisions.

The cause of the inelasticity of demand in the 2seller treatment remains unexplained. However, the fact that this pattern is observed when there are two sellers and three buyers, but not when there are three buyers and two sellers, helps to narrow down the possible explanations. One possibility is the presence of tacit collusion, which would be more feasible for two sellers than for three. Although collusion would obviously be discouraged by our random-matching protocol, the fact that prices shift significantly in the final periods of all four sessions suggests that this manipulation may have been only partially successful. ${ }^{12}$ However, we believe that the explanation has more to do with the nature of competition on the part of buyers. Under the 3 seller treatment, three units are to be sold to two buyers and in equilibrium there is an 83.3 percent chance that an individual buyer will be successful in making a purchase in a given period in equilibrium. In contrast, in the 2seller treatment, where there are three competing buyers, an individual buyer has only a 58.3 percent equilibrium probability of making a purchase. If buyers perceive missing out on a profitable trade as strong and salient negative feedback, the greater

\footnotetext{
${ }^{12}$ Dufwenberg and Gneezy (2000) also observe prices consistent with tacit collusion for duopolies but not triopolies in a random-matching design. Their markets did not feature frictions.
} 
probability of not obtaining a unit in the 2seller treatment may induce a greater degree of competition and price taking behavior on the part of buyers. This in turn can lead to prices closer to the buyers' true willingness-to-pay of 1000 than would occur in the BSW model, in which buyers are strategic. ${ }^{13}$

\footnotetext{
${ }^{13}$ This pattern has a close analogy in experimental research on auctions. When multiple units are sold to buyers who are each permitted to purchase one unit, the relative number of potential buyers and units available is a key determinant of whether prices are higher or lower than Nash equilibrium levels. When the number of bidders is relatively high compared to the number of units sold, prices are more likely to be higher than in equilibrium (see Cox et al., 1984).
} 


\section{References:}

Abrams, Eric, Martin Sefton and Abdullah Yavas (2000), “An Experimental Comparison of Two Search Models," Economic Theory 16, pp. 735-749.

Alger, Dan (1987), "Laboratory Tests of Equilibrium Predictions with Disequilibrium Data," Review of Economic Studies 54, pp. 105-145.

Burdett, Kenneth, Shouyong Shi and Randall Wright (2001), "Pricing and Matching with Frictions," Journal of Political Economy 109, pp. 1060-1085.

Cason, Timothy and Daniel Friedman (2003), "Buyer Search and Price Dispersion: A Laboratory Study," Journal of Economic Theory 112, pp. 232-260.

Cason, Timothy and Arlington Williams (1990), "Competitive Equilibrium Convergence in a Posted-Offer Market with Extreme Earnings Inequities," Journal of Economic Behavior and Organization 14, pp. 331-352.

Cox, James C., Vernon Smith, and James Walker, "Theory and Behavior of Multiple-Unit Discriminative Auctions", Journal of Finance 39, pp. 983-1010.

Davis Douglas and Charles Holt (1993), Experimental Economics (Princeton, NJ: Princeton University Press).

Davis, Douglas and Charles Holt (1996), "Consumer Search Costs and Market Performance," Economic Inquiry 34, pp. 133-151.

Davis, Douglas and Arlington Williams (1986), "The Effects of Rent Asymmetries in Posted Offer Markets," Journal of Economic Behavior and Organization 7, pp. 303-316.

Diamond, Peter (1971), “A Model of Price Adjustment," Journal of Economic Theory 3, pp. 156-168.

Dufwenberg, Martin and Uri Gneezy (2000), "Price Competition and Market Concentration: An Experimental Study," International Journal of Industrial Organization 18, pp. 7-22.

Fehr, Ernst and Klaus Schmidt (1999), "A Theory of Fairness, Competition, and Cooperation," Quarterly Journal of Economics 114, pp. 817-868.

Fischbacher, Urs (1999), "z-Tree. Toolbox for Readymade Economic Experiments," IEW Working paper 21, University of Zurich.

Fouraker, Lawrence and Sidney Siegel (1963), Bargaining Behavior (New York: McGraw-Hill).

Grether, David, Alan Schwartz and Louis Wilde (1988), "Uncertainty and Shopping Behavior: An Experimental Analysis," Review of Economic Studies 55, 323-342. 
Güth, Werner, Rolf Schmittberger and Bernd Schwarze (1982), “An Experimental Analysis of Ultimatum Bargaining," Journal of Economic Behavior and Organization 1, pp. 367-388

Ketcham, Jon, Vernon Smith and Arlington Williams (1984), "A Comparison of Posted-Offer and Double-Auction Pricing Institutions," Review of Economic Studies 51, pp. 595-614.

Montgomery, James (1991), "Equilibrium Wage Dispersion and Interindustry Wage Differentials," Quarterly Journal of Economics 106, pp. 163-179.

Noussair, Charles, Charles Plott and Raymond Riezman (1995), “An Experimental Investigation of the Patterns of International Trade," American Economic Review 85, pp. 462-491.

Plott, Charles and Vernon Smith (1978), "An Experimental Examination of Two Exchange Institutions," Review of Economic Studies 45, pp. 133-153.

Smith, Vernon (1982), "Microeconomic Systems as an Experimental Science," American Economic Review 71, pp. 923-955. 


\section{Appendix}

\section{Instructions for Experiment}

You are about to participate in an experiment in the economics of market decision making. The instructions are simple and if you follow them carefully and make good decisions you might earn a considerable amount of money. The currency used in the experiment is francs. All trading will be in terms of francs. Your francs will be converted to dollars at a rate of one dollar. You will be paid in cash at the end of the experiment. francs to

The experiment is divided into a series of 50 periods. After the $50^{\text {th }}$ period the experiment will end. Participants will have the role of either a buyer or a seller. The sellers will each have a single unit of a product to sell in each period. Buyers can make money every period that they are able to purchase a unit of the product. Each period, each participant will be assigned to a group at random. In other words, the computer will randomly select the other members of your group each period, so the other participants in your group will typically change each period. Each group will consist of 2 sellers and 3 buyers. However, you will remain a for the entire experiment. There are 25 participants in today's experiment, so there are 5 groups, with 5 randomly-changing participants in each group.

\section{Specific Instructions for Sellers}

During each period you will have a unit of the product to sell. Your earnings for the period will equal the price at which you sell your unit. If you do not sell your unit your earnings are zero for the period.

To sell your product, enter a price in the box labeled Your offer on your computer screen. Then select the [Make Offer] button. The price you enter must be a whole number and cannot be more than 1000 or less than 0 . You will not be able to observe the other sellers' prices until you make your own choice.

The buyers will then choose a seller to purchase from. If you are not chosen by any buyer, you do not make a sale for the period. If you are chosen by one or more buyers, you sell one unit for the period. At the end of the period, your computer screen will indicate the number of buyers who tried to buy from you, whether or not you sold your unit, your earnings for the period, and your total earnings so far for the experimental session. It will also show the prices offered by the other sellers in your group and the number of buyers that attempted to purchase from them. You will need to record some of this information on your Personal Record Sheet.

\section{Specific Instructions for Buyers}

During each period you have the opportunity to try to purchase one unit of the product. If you purchase a unit, your earnings will equal 1000 minus the price you paid for the unit. For 
example, if you purchase a unit at a price of 834 , your earnings are $1000-834=166$. If you do not purchase a unit, your earnings are zero for the period.

After all sellers have submitted their prices, the prices will be displayed to all buyers in your group. At this point, you may try to purchase a unit. To try to purchase a unit, use your computer screen and select one of the options in response to the question "What is your choice?" The options available to you are to purchase from any one of the sellers or not to purchase at all. After you have made a choice select the [OK] button.

If you are the only buyer to have chosen a particular seller, you definitely make a purchase from that seller. If more than one buyer chooses the same seller, each buyer has an equal chance of being able to purchase from that seller. For example, if you and one other buyer select seller Z, each of you has a $50 \%$ chance of being able to purchase a unit from her. The buyer who does not purchase a unit receives zero earnings for the period. The buyer who succeeds in purchasing is determined randomly, and is not based on how fast buyers choose a seller.

After all buyers have made their choices, the period ends. The upper half of your screen will then display the following information: the seller you chose (if any), the price she offered, the number of buyers who attempted to purchase from her, whether or not you made a purchase and your earnings for the period and for the experiment so far. The lower half of you screen will indicate the prices offered by all other sellers in your group and the number of buyers who attempted to purchase from each seller. You will need to record some of this information on your Personal Record Sheet. 
Personal Record Sheet for Buyer

Your Results

\begin{tabular}{|c|c|c|c|c|c|c|c|c|}
\hline Period & $\begin{array}{l}\text { Your } \\
\text { Seller's } \\
\text { Price (if } \\
\text { any) }\end{array}$ & $\begin{array}{l}\text { Number } \\
\text { of buyers } \\
\text { who tried } \\
\text { to } \\
\text { purchase } \\
\text { from } \\
\text { your } \\
\text { seller }\end{array}$ & $\begin{array}{l}\text { Your } \\
\text { earnings } \\
\text { this } \\
\text { period }\end{array}$ & $\begin{array}{l}\text { Total } \\
\text { earnings } \\
\text { this } \\
\text { session }\end{array}$ & $\begin{array}{l}\text { Other } \\
\text { Seller's } \\
\text { Price }\end{array}$ & $\begin{array}{l}\text { Number } \\
\text { of buyers } \\
\text { who tried } \\
\text { to } \\
\text { purchase } \\
\text { from this } \\
\text { other } \\
\text { seller }\end{array}$ & $\begin{array}{l}\text { Other } \\
\text { Seller's } \\
\text { Price }\end{array}$ & $\begin{array}{l}\text { Number } \\
\text { of buyers } \\
\text { who tried } \\
\text { to } \\
\text { purchase } \\
\text { from this } \\
\text { other } \\
\text { seller }\end{array}$ \\
\hline 1 & & & & & & & & \\
\hline 2 & & & & & & & & \\
\hline 3 & & & & & & & & \\
\hline 4 & & & & & & & & \\
\hline 5 & & & & & & & & \\
\hline 6 & & & & & & & & \\
\hline 7 & & & & & & & & \\
\hline 8 & & & & & & & & \\
\hline 9 & & & & & & & & \\
\hline 10 & & & & & & & & \\
\hline 11 & & & & & & & & \\
\hline 12 & & & & & & & & \\
\hline 13 & & & & & & & & \\
\hline 14 & & & & & & & & \\
\hline 15 & & & & & & & & \\
\hline 16 & & & & & & & & \\
\hline 17 & & & & & & & & \\
\hline 18 & & & & & & & & \\
\hline 19 & & & & & & & & \\
\hline 20 & & & & & & & & \\
\hline
\end{tabular}


Personal Record Sheet for Seller

Your Results

\begin{tabular}{|c|c|c|c|c|c|c|c|c|}
\hline Period & $\begin{array}{l}\text { Your } \\
\text { Price }\end{array}$ & $\begin{array}{l}\text { Number } \\
\text { of } \\
\text { buyers } \\
\text { who } \\
\text { tried to } \\
\text { buy } \\
\text { from } \\
\text { you }\end{array}$ & $\begin{array}{l}\text { Your } \\
\text { earnings } \\
\text { this } \\
\text { period }\end{array}$ & $\begin{array}{l}\text { Total } \\
\text { earnings } \\
\text { this } \\
\text { session }\end{array}$ & $\begin{array}{l}\text { Other } \\
\text { Seller's } \\
\text { Price }\end{array}$ & $\begin{array}{l}\text { Number } \\
\text { of } \\
\text { buyers } \\
\text { who } \\
\text { tried to } \\
\text { buy from } \\
\text { that } \\
\text { seller }\end{array}$ & $\begin{array}{l}\text { Other } \\
\text { Seller's } \\
\text { Price }\end{array}$ & $\begin{array}{l}\text { Number } \\
\text { of } \\
\text { buyers } \\
\text { who } \\
\text { tried to } \\
\text { buy from } \\
\text { that } \\
\text { seller }\end{array}$ \\
\hline 41 & & & & & & & & \\
\hline 42 & & & & & & & & \\
\hline 43 & & & & & & & & \\
\hline 44 & & & & & & & & \\
\hline 45 & & & & & & & & \\
\hline 46 & & & & & & & & \\
\hline 47 & & & & & & & & \\
\hline 48 & & & & & & & & \\
\hline 49 & & & & & & & & \\
\hline 50 & & & & & & & & \\
\hline
\end{tabular}

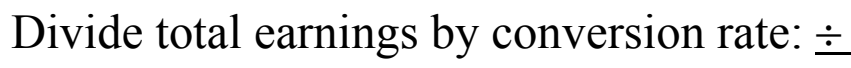

Total earnings in dollars: $\$$ 
Table 1: The Experimental Sessions

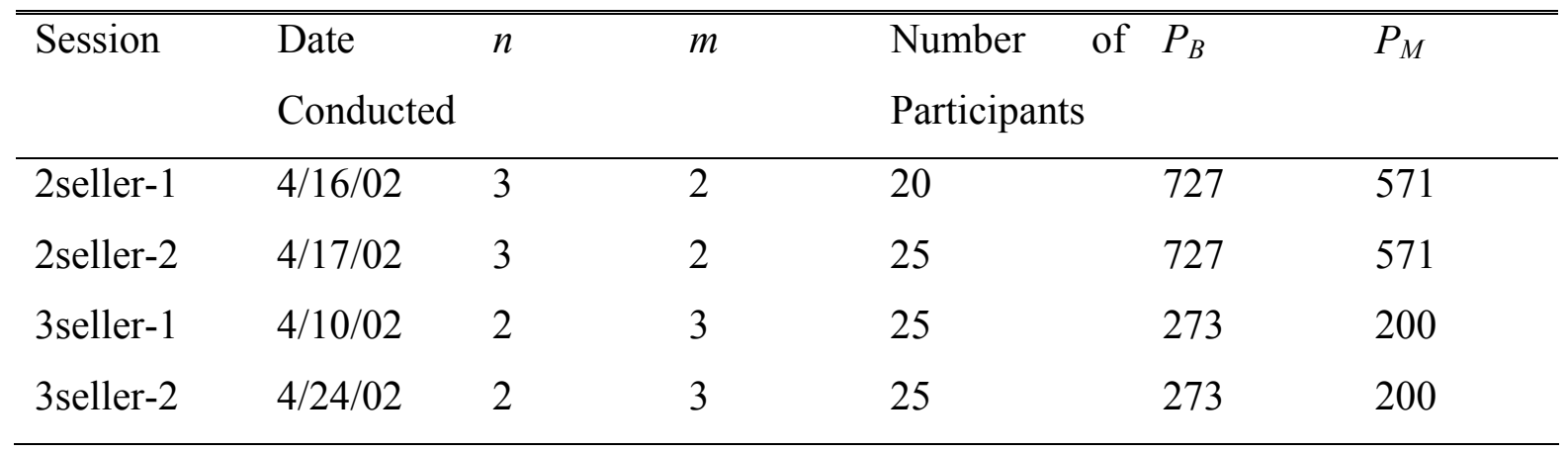


Table 2: Convergence Patterns Over Time of Posted Prices and Transaction Prices

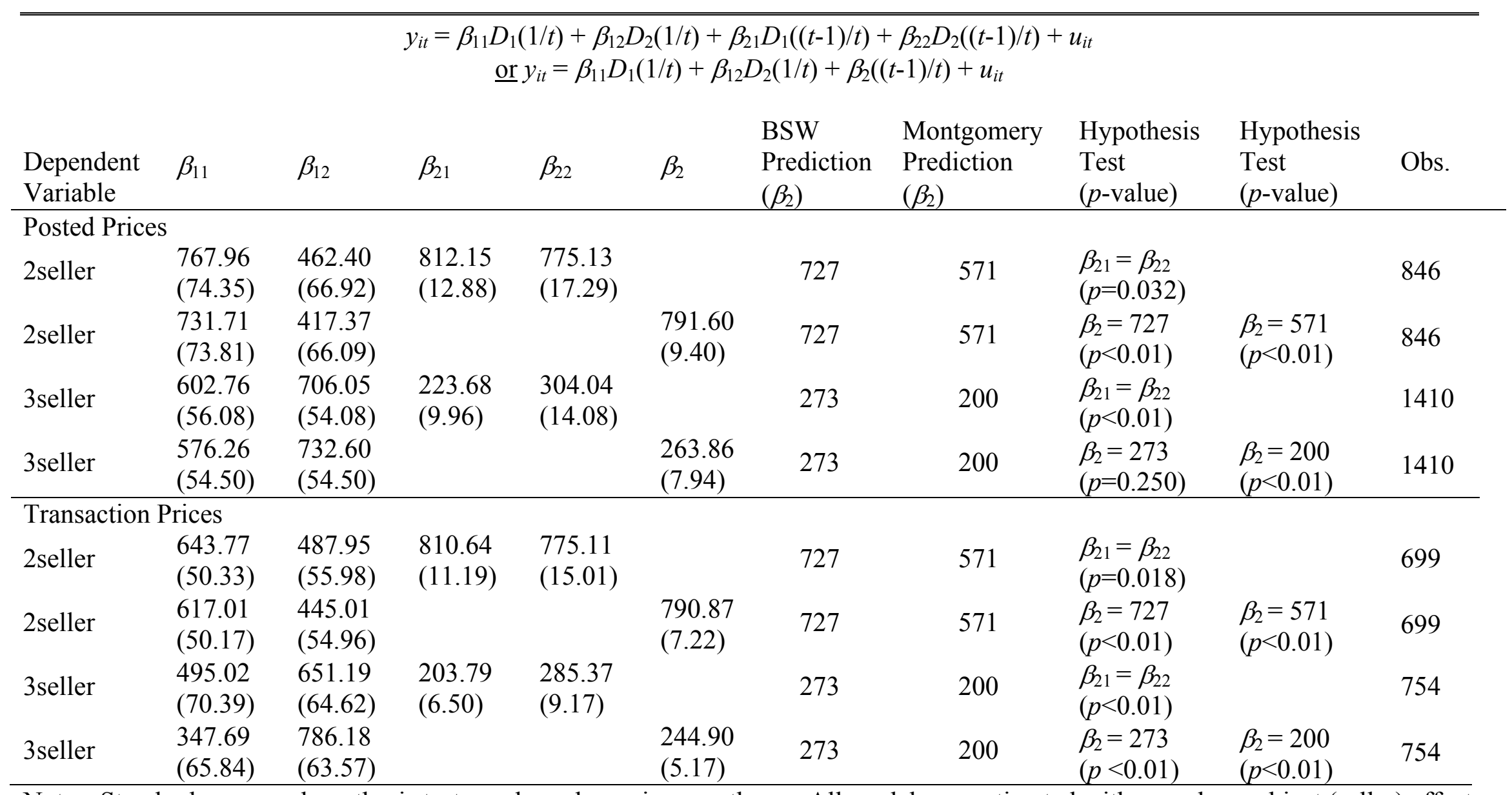

Notes: Standard errors or hypothesis test $p$-values shown in parentheses. All models are estimated with a random subject (seller) effect error term, with a correction for significant first-order autocorrelation. All models drop the final two periods 49-50. 
Table 3: Convergence Patterns Over Time of Posted Price Variance and the Matching Rate

\begin{tabular}{|c|c|c|c|c|c|c|c|c|c|}
\hline \multirow[b]{2}{*}{$\begin{array}{l}\text { Dependent } \\
\text { Variable }\end{array}$} & \multirow[b]{2}{*}{$\beta_{11}$} & \multirow[b]{2}{*}{$\beta_{12}$} & \multicolumn{5}{|c|}{$\begin{array}{c}y_{i t}=\beta_{11} D_{1}(1 / t)+\beta_{12} D_{2}(1 / t)+\beta_{21} D_{1}((t-1) / t)+\beta_{22} D_{2}((t-1) / t)+u_{i t} \\
\text { or } y_{i t}=\beta_{11} D_{1}(1 / t)+\beta_{12} D_{2}(1 / t)+\beta_{2}((t-1) / t)+u_{i t}\end{array}$} & \multirow[b]{2}{*}{$\begin{array}{l}\text { Hypothesis Test } \\
(p \text {-value })\end{array}$} & \multirow[b]{2}{*}{ Observations } \\
\hline & & & $\beta_{21}$ & $\beta_{22}$ & $\beta_{2}$ & $\begin{array}{l}\text { BSW } \\
\text { Prediction }\left(\beta_{2}\right)\end{array}$ & $\begin{array}{l}\text { Montgomery } \\
\text { Prediction }\left(\beta_{2}\right)\end{array}$ & & \\
\hline \multicolumn{10}{|c|}{ Posted Price Variance (Tobit Model) } \\
\hline 2 seller & $\begin{array}{l}13498 \\
(3407)\end{array}$ & $\begin{array}{l}26147 \\
(3201)\end{array}$ & $\begin{array}{l}-165 \\
(681)\end{array}$ & $\begin{array}{l}1823 \\
(637)\end{array}$ & & 0 & 0 & $\begin{array}{l}\beta_{21}=\beta_{22} \\
(p=0.029)\end{array}$ & 432 \\
\hline 3 seller & $\begin{array}{l}21297 \\
(4923)\end{array}$ & $\begin{array}{l}13197 \\
(4876)\end{array}$ & $\begin{array}{l}4874 \\
(1046)\end{array}$ & $\begin{array}{l}2285 \\
(1001)\end{array}$ & & 0 & 0 & $\begin{array}{l}\beta_{21}=\beta_{22} \\
(p=0.057)\end{array}$ & 480 \\
\hline 3 seller & $\begin{array}{l}23537 \\
(4806)\end{array}$ & $\begin{array}{l}10929 \\
(4731)\end{array}$ & & & $\begin{array}{l}3577 \\
(766) \\
\end{array}$ & 0 & 0 & $\begin{array}{l}\beta_{2}=0 \\
(p<0.01)\end{array}$ & 480 \\
\hline \multicolumn{10}{|c|}{ Probability of Two Matches (Probit Model) } \\
\hline 3 seller & $\begin{array}{l}-0.668 \\
(0.486)\end{array}$ & $\begin{array}{l}-0.073 \\
(0.469)\end{array}$ & $\begin{array}{l}0.561 \\
(0.099)\end{array}$ & $\begin{array}{l}0.275 \\
(0.095)\end{array}$ & & 0.43 & 0.43 & $\begin{array}{l}\beta_{21}=\beta_{22} \\
(p=0.037)\end{array}$ & 480 \\
\hline 3 seller & $\begin{array}{l}-0.412 \\
(0.462)\end{array}$ & $\begin{array}{l}-0.311 \\
(0.454)\end{array}$ & & & $\begin{array}{l}0.415 \\
(0.068)\end{array}$ & 0.43 & 0.43 & $\begin{array}{l}\beta_{2}=0.43 \\
(p=0.820)\end{array}$ & 480 \\
\hline
\end{tabular}

Notes: Standard errors or hypothesis test $p$-values shown in parentheses. All models drop the final two periods 49-50. 
Table 4: Random Effects Probit Models of Buyer $i$ 's Decision to Approach Low-Price Seller Dependent Variable: Probability that Buyer Approached Low-Priced Seller (Marginal Effects Shown, Evaluated at Means of the Explanatory Variables)

\begin{tabular}{|c|c|c|c|c|}
\hline \multirow[b]{2}{*}{ Variable } & \multicolumn{2}{|c|}{ 2seller } & \multicolumn{2}{|c|}{ 3seller } \\
\hline & $(1)$ & (2) & (3) & $(4)$ \\
\hline $\begin{array}{l}\text { Probability of Approaching Low- } \\
\text { Price Seller }(\theta) \text { under BSW model } \\
\text { for sellers' actual price choices }\end{array}$ & $\begin{array}{l}0.613 * * \\
(0.110)\end{array}$ & $\begin{array}{l}0.613 * * \\
(0.115)\end{array}$ & $\begin{array}{l}1.173 * * \\
(0.293)\end{array}$ & $\begin{array}{l}1.178 * * \\
(0.299)\end{array}$ \\
\hline $\begin{array}{l}D_{1}^{i}=1 \text { if Buyer } i \text { Approached the } \\
\text { Low-Price Seller Last Period, } \\
=0 \text { otherwise }\end{array}$ & $\begin{array}{l}-0.015 \\
(0.025)\end{array}$ & & $\begin{array}{l}0.188 * * \\
(0.047)\end{array}$ & \\
\hline $\begin{array}{l}D_{2}^{i}=1 \text { iff Buyer } i \text { Succeeded in } \\
\text { Buying from the Low-Price Seller } \\
\text { Last Period, } \\
=0 \text { otherwise }\end{array}$ & & $\begin{array}{l}-0.004 \\
(0.035)\end{array}$ & & $\begin{array}{l}0.231 * * \\
(0.080)\end{array}$ \\
\hline$D_{3}^{i}=1$ iff Buyer $i$ Failed when & & -0.026 & & 0.075 \\
\hline $\begin{array}{l}\text { Trying to Buy from the Low-Price } \\
\text { Seller Last Period } \\
=0 \text { otherwise }\end{array}$ & & $(0.028)$ & & $(0.072)$ \\
\hline $\begin{array}{l}\text { Number of Other Buyers who } \\
\text { Approached the Low-Price Seller } \\
\text { Last Period }\end{array}$ & $\begin{array}{l}-0.070 * * \\
(0.022)\end{array}$ & $\begin{array}{l}-0.066^{* *} \\
(0.022)\end{array}$ & $\begin{array}{l}-0.223 * * \\
(0.060)\end{array}$ & $\begin{array}{l}-0.183^{*} \\
(0.087)\end{array}$ \\
\hline $\operatorname{Ln}($ Period $)$ & $\begin{array}{l}0.015 \\
(0.016)\end{array}$ & $\begin{array}{l}0.015 \\
(0.017)\end{array}$ & $\begin{array}{l}0.047 \\
(0.025)\end{array}$ & $\begin{array}{l}0.042 \\
(0.026)\end{array}$ \\
\hline Intercept & $\begin{array}{l}-0.223 \\
(0.115)\end{array}$ & $\begin{array}{l}-0.227 \\
(0.129)\end{array}$ & $\begin{array}{l}-0.538 * * \\
(0.193)\end{array}$ & $\begin{array}{l}-0.547 * * \\
(0.195)\end{array}$ \\
\hline Observations & 1206 & 1206 & 786 & 786 \\
\hline Log-likelihood & -726.1 & -725.9 & -397.2 & -394.9 \\
\hline $\begin{array}{l}\text { Restricted } \\
\text { likelihood }\end{array} \quad$ slopes=1) Log- & -802.2 & -802.2 & -544.4 & -544.4 \\
\hline
\end{tabular}

Notes: Standard errors in parentheses. ${ }^{*}$ denotes significantly different from zero at 5-percent level; ** denotes significantly different from zero at 1-percent level. 
Table 5: Random Effects Model of Individual Seller Price Changes

Dependent Variable: $P_{t}^{i}-P_{t-1}^{i}$, Change in Seller $i$ 's Price from period $t$-1 to period $t$

\begin{tabular}{lll}
\hline \hline Variable & 2seller & 3seller \\
\hline$D_{1}^{i}=1$ iff this Seller Sold a Unit Last Period, 0 & $23.79^{* *}$ & $31.90^{* *}$ \\
otherwise & $(3.55)$ & $(4.53)$ \\
Average of other Sellers' Prices over the Previous & $-0.075^{* *}$ & -0.149 \\
Five Periods & $(0.012)$ & $(0.310)$ \\
Indicator=1 iff a Friction (i.e., total units sold $<2)$ & 1.25 & 7.48 \\
Occurred in this Seller's Market Last Period & $(2.81)$ & $(4.74)$ \\
Intercept & $43.78^{* *}$ & -17.38 \\
& $(9.80)$ & $(9.38)$ \\
\hline Observations & 774 & 1260 \\
$\mathrm{R}^{2}$ & 0.135 & 0.04 \\
\hline
\end{tabular}

Notes: Standard errors in parentheses. ${ }^{*}$ denotes significantly different from zero at 5-percent level; ** denotes significantly different from zero at 1-percent level. 


\section{Figure 1a: Mean Posted Prices for 4 Sessions}

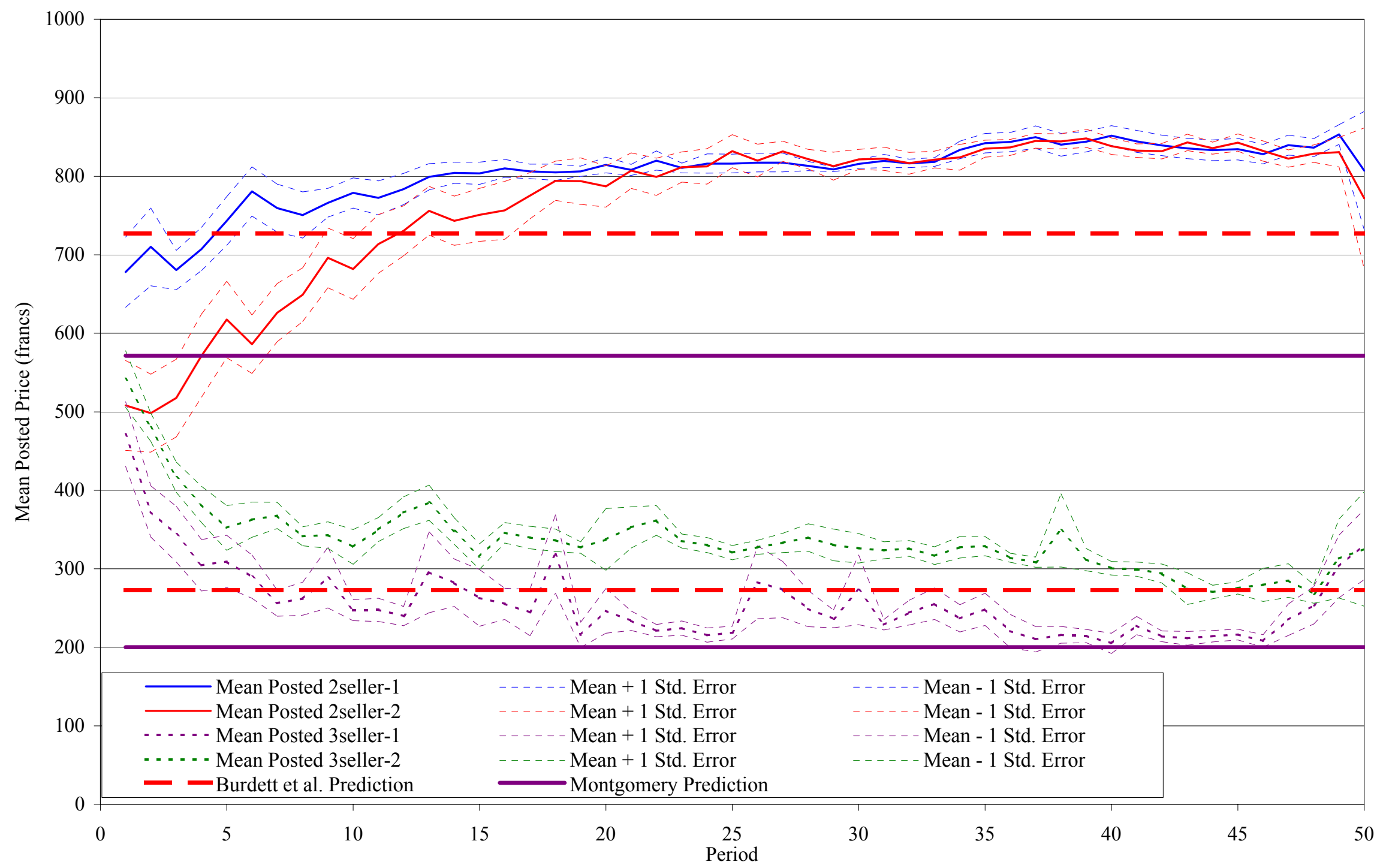




\section{Figure 1b: Mean Transaction Prices for 4 Sessions}

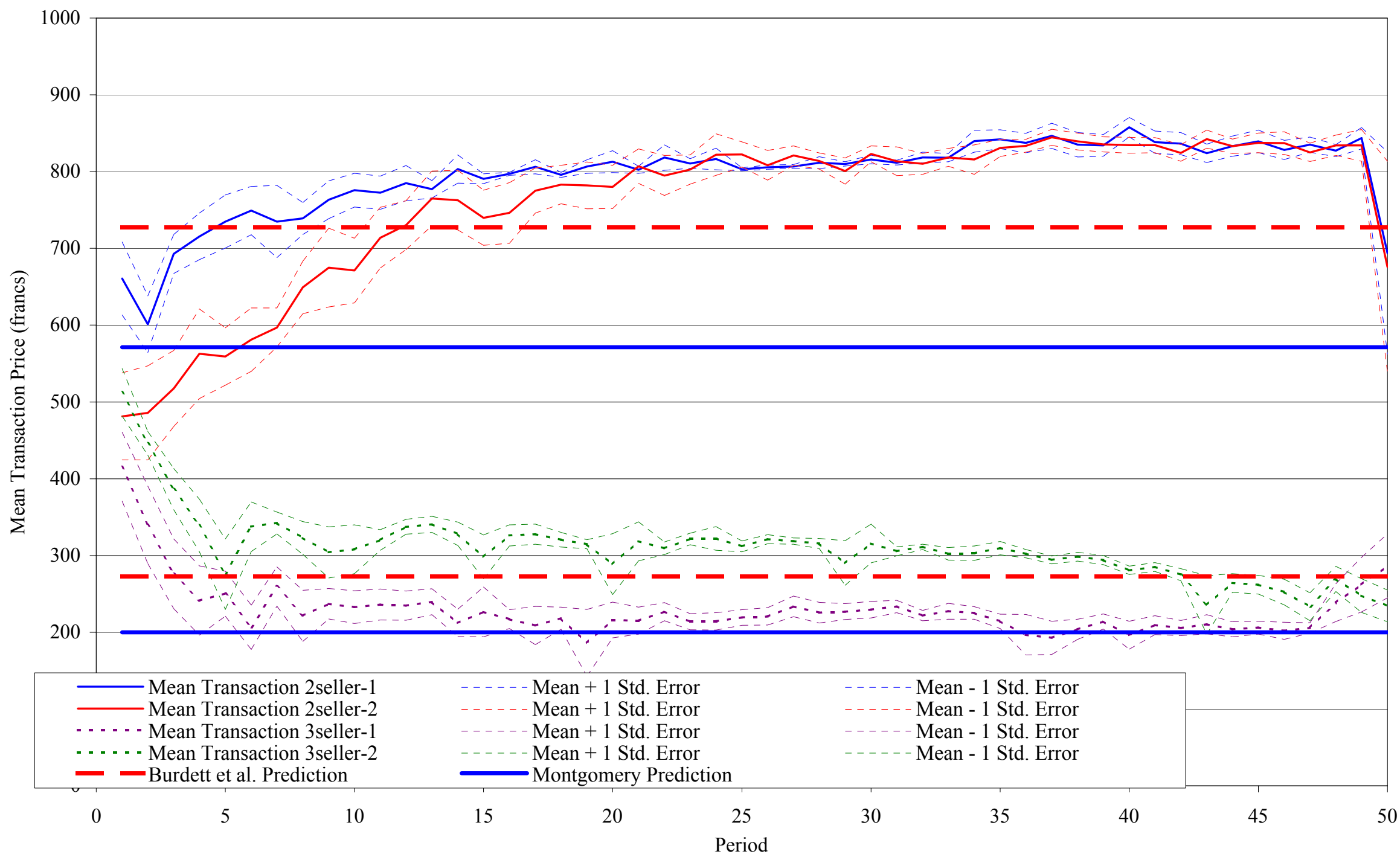


Figure 2: Average Number of Buyer-Seller Matches per 5-Trader Group (2 maximum)

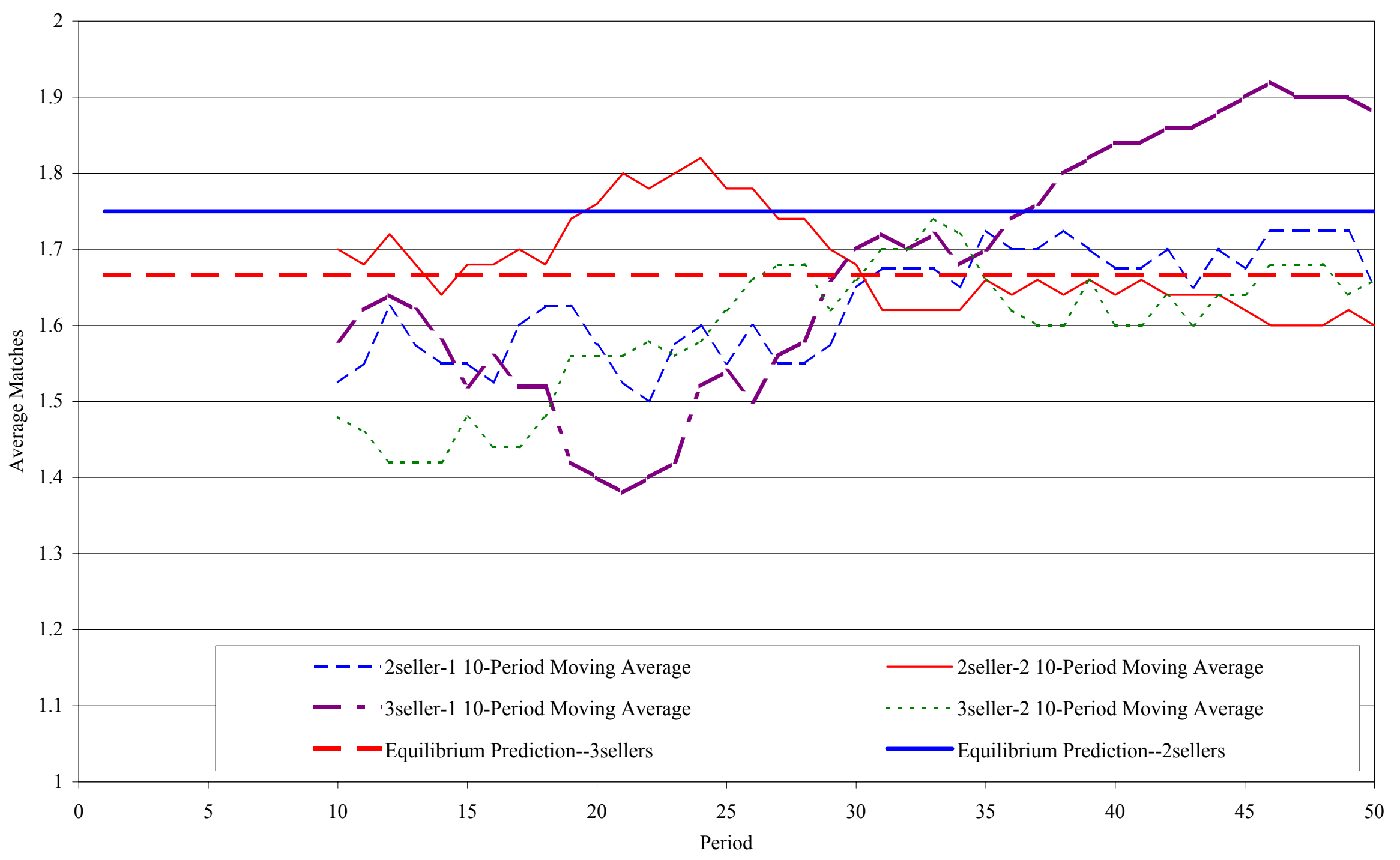


Figure 3: Probability of Buying from Seller B in Mixed Strategy Equilibrium (2 sellers, 3 buyers)

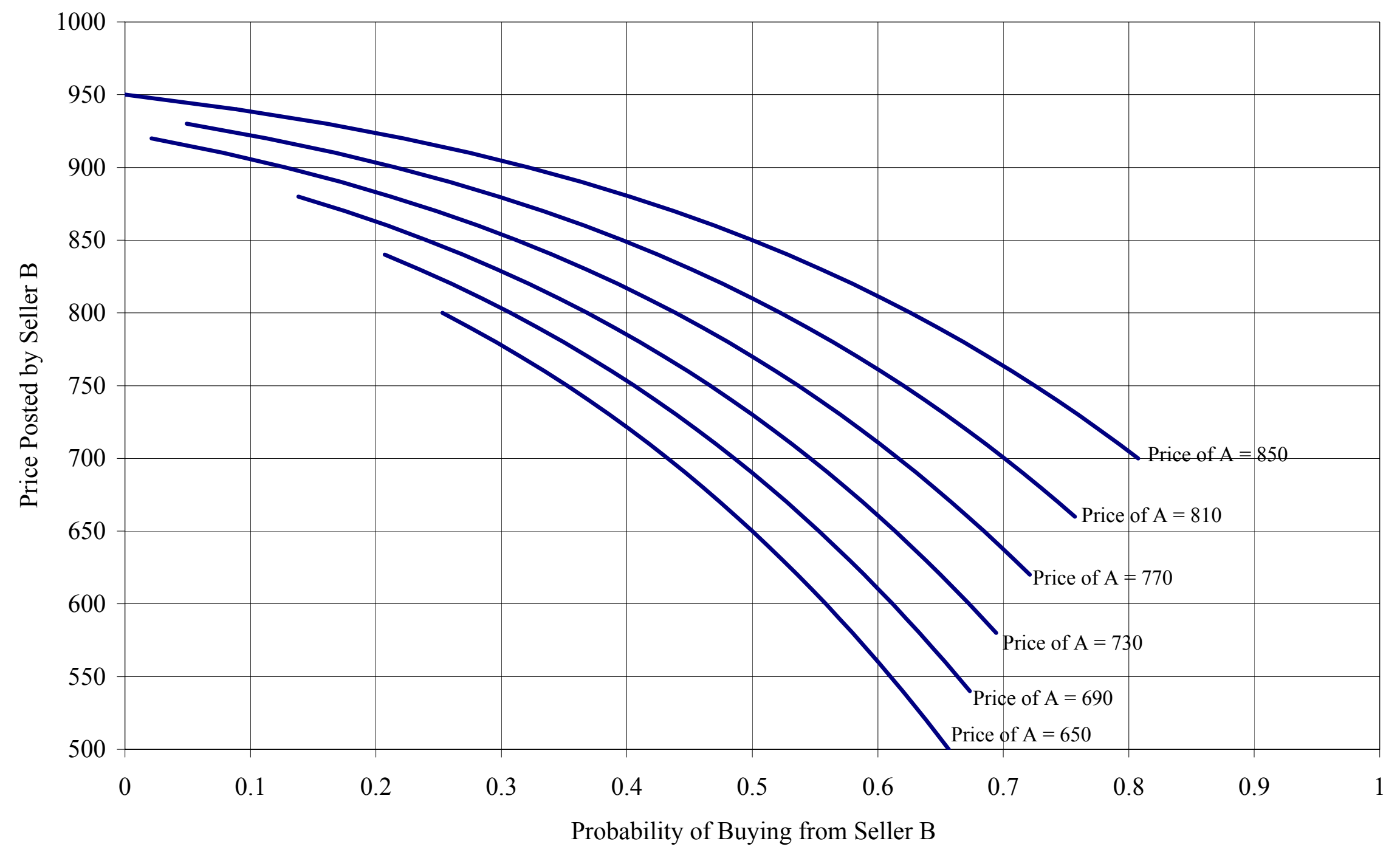


Figure 4: Predicted and Observed Rate that Buyers Approach the Low-Price Seller (2seller treatment)

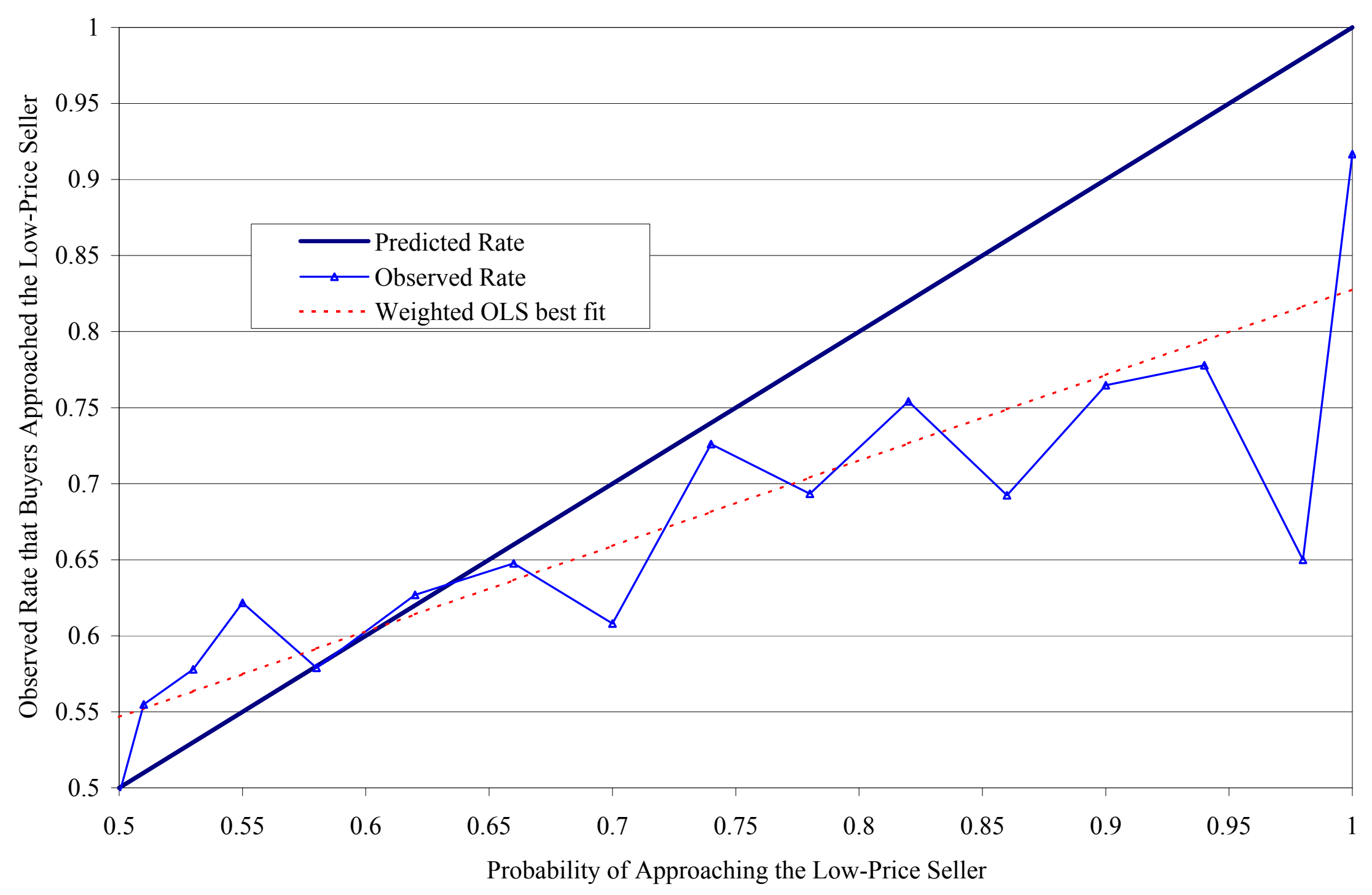

